\title{
MAXIMAL OPERATORS OF $T$ MEANS WITH RESPECT TO WALSH-KACZMARZ SYSTEM
}

\author{
NATA Gogolashvili And GeORge TePhnAdZE*
}

\begin{abstract}
In this paper we prove and discuss some new $\left(H_{p}, L_{p, \infty}\right)$ type inequalities of the maximal operators of $T$ means with monotone coefficients with respect to Walsh-Kaczmarz system. It is also proved that these results are the best possible in a special sense. As applications, both some well-known and new results are pointed out. In particular, we apply these results to prove a.e. convergence of such $T$ means.
\end{abstract}

Mathematics subject classification (2020): 42C10.

Keywords and phrases: Walsh-Kaczmarz system, $T$ means, martingale Hardy space.

\section{REFERENCES}

[1] L. Baramidze, L. E. Persson, G. Tephnadze and P. Wall, Srtong summability and Boundedness of Maximal operators of Vilenkin-Nörlund means with non-increasing coefficients, J. Inequal. Appl., 2016, doi:10.1186/s13660-016-1182-1.

[2] I. Blahota AND K. NAGY, Approximation by $\Theta$-means of Walsh-Fourier series, Anal. Math., 44, 1 (2018) 57-71.

[3] I. Blahota, K. Nagy and G. Tephnadze, Approximation by Marcinkiewicz $\Theta$-means of double Walsh-Fourier series, Math. Inequal. Appl., 22, 3 (2019) 837-853.

[4] I. Blahota AND G. GÁT, Norm summability of Nörlund logarithmic means on unbounded Vilenkin groups, Anal. Theory Appl., 24, 1 (2008), 1-17.

[5] I. Blahota And G. Tephnadze, On the $(C, \alpha)$-means with respect to the Walsh system, Anal. Math., 40, (2014), 161-174.

[6] I. Blahota and G. TephnadZe, Strong convergence theorem for Vilenkin-Fejér means, Publ. Math. Debrecen, 85, (1-2) (2014), 181-196.

[7] I. Blahota, L. E. Persson And G. TePhnadze, On the Nörlund means of Vilenkin-Fourier series, Czechoslovak Math. J. 65, 4 (2015), 983-1002.

[8] I. Blahota, K. Nagy, L. E. Persson, G. Tephnadze, A sharp boundedness result concerning some maximal operators of partial sums with respect to Vilenkin systems, Georgian Math., J., 26, 3 (2019), 351-360.

[9] G. GÁt, On $(C, 1)$ summability of integrable functions with respect to the Walsh-Kaczmarz system, Studia Math., 130, 2 (1998), 135-148.

[10] G. GÁt AND U. GoginaVA, A weak type inequality for the maximal operator of $(C, \alpha)$-means of Fourier series with respect to the Walsh-Kaczmarz system, Acta Math. Hungar., 125, 1-2 (2009), 6583.

[11] U. Goginava, The maximal operator of the Fejér means of the character system of the p-series field in the Kaczmarz rearrangement, Publ. Math. Debrecen, 71, 1-2, (2007), 43-55.

[12] U. GoginaVA AND K. NAGY, On the maximal operator of $(C, \alpha)$-means of Walsh-Kaczmarz-Fourier series, Ukrainian Math. J., 62, 2 (2010), 175-185.

[13] N. Gogolashvili, K. Nagy and G. Tephnadze, Strong convergence theorem for WalshKaczmarz-Fejér means, Mediterr. J. Math., 18, 2 (2021), doi:10.1007/s00009-020-01682-5.

[14] D. Luk Kassen, L.-E. Persson, G. Tephnadze and G. Tutberidze, Some inequalities related to strong convergence of Riesz logarithmic means of Vilenkin-Fourier series, J. Inequal. Appl., 2020, https://doi.org/10.1186/s13660-020-02342-8. 
[15] I. Marcinkiewicz And A. Zygmund, On the summability of double Fourier series, Fund. Math. 32, (1939), 112-132.

[16] N. Memić, L. E. Persson And G. Tephnadze, A note on the maximal operators of VilenkinNörlund means with non-increasing coefficients, Stud. Sci. Math. Hung., 53, 4 (2016) 545-556.

[17] K. Nagy and U. Goginava, Maximal operators of Walsh-Kaczmarz logarithmic means, Complex Var. Elliptic Equ., 58, 9 (2013), 1173-1182.

[18] C. N. Moore, Summable series and convergence factors, Dover Publications, Inc., New York 1966.

[19] F. Móricz AND A. H. SIDDIQI, Approximation by Nörlund means of Walsh-Fourier series, J. Approx. Theory, 70, 3 (1992), 375-389.

[20] K. NAGY, Approximation by Cesàro means of negative order of Walsh-Kaczmarz-Fourier series, East J. Approx., 16, 3 (2010), 297-311.

[21] K. NAGY, Approximation by Nörlund means of quadratical partial sums of double Walsh-Fourier series, Anal. Math., 36, 4 (2010), 299-319.

[22] K. NAGY, Approximation by Nörlund means of double Walsh-Fourier series for Lipschitz functions, Math. Inequal. Appl., 15, 2 (2012), 301-322.

[23] K. NAGy And G. TePhnAdZE, Approximation by Walsh-Kaczmarz-Marcinkiewicz means on the Hardy space $\mathrm{H}_{2 / 3}$, Bulletin of TICMI, 18, 1 (2014), 110-121.

[24] K. Nagy And G. Tephnadze, On the Walsh-Marcinkiewicz means on the Hardy space, Cent. Eur. J. Math., 12, 8 (2014), 1214-1228.

[25] K. Nagy and G. TePhnadZe, Approximation by Walsh-Marcinkiewicz means on the Hardy space, Kyoto J. Math., 54, 3 (2014), 641-652.

[26] K. Nagy and G. Tephnadze, Kaczmarz-Marcinkiewicz means and Hardy spaces, Acta math. Hung., 149, 2 (2016), 346-374.

[27] K. NAGy And G. TePhnAdZE, Strong convergence theorem for Walsh-Marcinkiewicz means, Math. Inequal. Appl., 19, 1 (2016), 185-195.

[28] L. E. Persson, G. TePhnadze And P. WALl, Maximal operators of Vilenkin-Nörlund means, J. Fourier Anal. Appl., 21, 1 (2015), 76-94.

[29] L. E. Persson, G. Tephnadze And P. Wall, On the Nörlund logarithmic means with respect to Vilenkin system in the martingale Hardy space $H_{1}$, Acta math. Hung., 154, 2 (2018), 289-301.

[30] L. E. Persson, G. Tephnadze And G. Tutberidze, On the boundedness of subsequences of Vilenkin-Fejér means on the martingale Hardy spaces, Operators and matrices, 14, 1 (2020), 283-294.

[31] L. E. Persson, G. Tephnadze, G. Tutberidze And P. Wall, Strong summability result of Vilenkin-Fejér means on bounded Vilenkin groups, Ukr. Math. J., 73, 4 (2021), 544-555.

[32] F. SCHIPP, Pointwise convergence of expansions with respect to certain product systems, Anal. Math., 2, 1 (1976), 65-76.

[33] F. Schipp, W. R. WAde, P. Simon And J. PÁL, Walsh series. An introduction to dyadic harmonic analysis. With the collaboration of J. Pál, Adam Hilger, Ltd., Bristol, 1990.

[34] P. Simon, On the Cesáro summability with respect to the Walsh-Kaczmarz system, J. Approx. Theory, 106, 2 (2000), 249-261.

[35] P. Simon, Cesáro summability with respect to two-parameter Walsh systems, Monatsh. Math., 131, 4 (2000), 321-334.

[36] V. A. Skvorcov, On Fourier series with respect to the Walsh-Kaczmarz system, Anal. Math., 7, 2 (1981), 141-150.

[37] A. ŠNEİDER, On series of Walsh functions with monotonic coefficients, (Russian) Izvestiya Akad. Nauk SSSR. Ser. Mat. 12, (1948) 179-192.

[38] G. Tephnadze, On the maximal operators of Kaczmarz-Nörlund means, Acta Math. Acad. Paed. Nyíreg., 31, (2015), 259-271.

[39] G. TePhnADZE, On the maximal operators of Walsh-Kaczmarz-Fejér means, Period. Math. Hungar., 67, 1 (2013), 33-45.

[40] G. Tephnadze, Approximation by Walsh-Kaczmarz-Fejér means on the Hardy space, Acta Math., Sci. Ser. B Engl. Ed., 34, 5 (2014) 1593-1602.

[41] G. Tephnadze, Fejér means of Vilenkin-Fourier series, Studia Sci. Math. Hungar., 49, 1 (2012), 79-90.

[42] G. TEPhNADZE, The maximal operators of logarithmic means of one-dimensional Vilenkin-Fourier series, Acta Math. Acad. Paedagog. Nyházi., (N. S.) 27, 2 (2011), 245-256. 
[43] G. Tephnadze, On the maximal operators of Kaczmarz-Nörlund means, Acta Math. Acad. Paed. Nyíreg., 31, (2015), 259-271.

[44] G. Tephnadze, G. Tutberidze, A note on the maximal operators of the Nörlund logaritmic means of Vilenkin-Fourier series, Transactions of A. Razmadze Math. Inst., 174, 1 (2020), 1070-112.

[45] G. TUtBERIDZE, Maximal operators of T means with respect to the Vilenkin system, Nonlinear Studies, 27, 4 (2020), 1-11.

[46] G. TUTBERIDZE, Modulus of continuity and boundedness of subsequences of Vilenkin-Fejér means in the martingale Hardy spaces, Georgian Math. J., (to appear).

[47] W. S. Young, On the a.e. convergence of Walsh-Kaczmarz-Fourier series, Proc. Amer. Math. Soc., 44, (1974), 353-358.

[48] F. WEISZ, Martingale Hardy spaces and their applications in Fourier analysis, Lecture Notes in Mathematics, 1568, Springer-Verlag, Berlin, 1994.

[49] F. WeIsz, Summability of multi-dimensional Fourier series and Hardy spaces, Mathematics and its Applications, 541, Kluwer Academic Publishers, Dordrecht, 2002.

[50] F. WEISZ, $\theta$-summability of Fourier series, Acta Math. Hungar., 103, 1-2 (2004), 139-175.

[51] F. WeISZ, $\theta$-summation and Hardy spaces, J. Approx. Theory, 107, (2000) 121-142.

[52] F. WeIsz, Several dimensional $\theta$-summability and Hardy spaces, Math. Nachr., 230, (2001) 159180.

[53] F. WeISZ, Marcinkiewicz- $\theta$-summability of double Fourier series, Annales Univ. Sci. Budapest., Sect. Comp., 24 (2004) 103-118.

[54] F. WEIsz, Marcinkiewicz- $\theta$-summability of Fourier transforms, Acta Math. Hungar., 96, 1-2 (2002) $149-160$. 